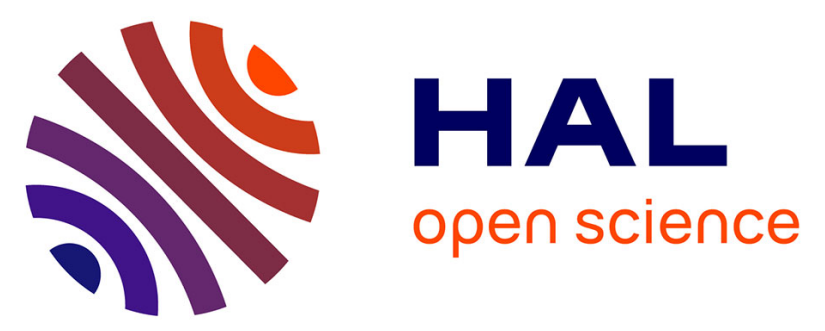

\title{
Single laser shot photoinduced phase transition of rubidium manganese hexacyanoferrate investigated by X-ray diffraction
}

Giovanni Azzolina, Eric Collet, Céline Mariette, Marco Cammarata, Elzbieta Trzop, Mathias Sander, Matteo Levantino, Kosuke N Nakagawa, Hiroko Tokoro, Shin-Ichi Ohkoshi, et al.

\section{To cite this version:}

Giovanni Azzolina, Eric Collet, Céline Mariette, Marco Cammarata, Elzbieta Trzop, et al.. Single laser shot photoinduced phase transition of rubidium manganese hexacyanoferrate investigated by X-ray diffraction. European Journal of Inorganic Chemistry, 2019, 2019 (27), pp.3142-3147. 10.1002/ejic.201801478 . hal-02017137

\section{HAL Id: hal-02017137 https://hal.science/hal-02017137}

Submitted on 13 Feb 2019

HAL is a multi-disciplinary open access archive for the deposit and dissemination of scientific research documents, whether they are published or not. The documents may come from teaching and research institutions in France or abroad, or from public or private research centers.
L'archive ouverte pluridisciplinaire HAL, est destinée au dépôt et à la diffusion de documents scientifiques de niveau recherche, publiés ou non, émanant des établissements d'enseignement et de recherche français ou étrangers, des laboratoires publics ou privés. 


\title{
Single laser shot photoinduced phase transition of rubidium manganese hexacyanoferrate investigated by $\mathrm{X}$-ray diffraction
}

\author{
Giovanni Azzolina, ${ }^{[a]}$ Eric Collet, ${ }^{[a]}$ Céline Mariette, ${ }^{[a]}$ Marco Cammarata, ${ }^{[a]}$ ElzbietaTrzop, ${ }^{[a]}$ Mathias \\ Sander, ${ }^{[b]}$ Matteo Levantino, ${ }^{[b]}$ Kosuke Nakagawa, ${ }^{[c]}$ Hiroko Tokoro, ${ }^{[d]}$ Shin-ichi Ohkoshi, ${ }^{[c]}$ \\ Roman Bertoni, ${ }^{*[a]}$
}

\begin{abstract}
We study by X-ray diffraction the phase transition of microcrystals of rubidium manganese hexacyanoferrate, for which combined electron transfer and structural reorganization are responsible for a change of magnetic properties. The $\mathrm{Rb}_{0.94} \mathrm{Mn}\left[\mathrm{Fe}(\mathrm{CN})_{6}\right]_{0.98} \cdot 2.5 \mathrm{H}_{2} \mathrm{O}$ system undergoes a phase transition between the tetragonal phase $\mathrm{Fe}^{\prime \prime}(\mathrm{S}=0)-\mathrm{CN}-\mathrm{Mn}{ }^{\prime \prime \prime}(\mathrm{S}=2)$ and the cubic $\mathrm{Fe}^{\prime \prime \prime}(\mathrm{S}=1 / 2)-\mathrm{CN}-\mathrm{Mn}^{\prime \prime}(\mathrm{S}=5 / 2)$ phases. The thermal equilibrium phase transition shows a broad regime of bistability, responsible for the appearance of a thermal hysteresis in the $\approx 185-300 \mathrm{~K}$ temperature range. We used a deposited film to study by X-ray diffraction the switching from the tetragonal phase to the cubic phase, induced inside the thermal hysteresis by a single laser shot of tunable power. Compared to previous measurements using local probes, our results show that the ns laser pulse induces a stable long-range ordered cubic phase when conversion is partial or complete.
\end{abstract}

\section{Introduction}

The possibility to tune the physical and chemical properties of materials with light irradiation opens the doors to many different technological applications like optical sensors or memory devices as examples. Optical control of materials was a key scientific challenge for many years especially down to ultrafast timescales. ${ }^{[1]}$ Molecular-based materials show various types of functionalities that may switch under photoexcitation, ${ }^{[2]}$ like ferroelectric or insulator-metal charge-transfer systems, ${ }^{[3]}$ photochromic materials ${ }^{[4]}$ or spin-crossover complexes. ${ }^{[5]}$ Prussian Blue Analogues (PBA) consisting in cyanide-bridged bimetallic assemblies ${ }^{[6]}$ are also very promising materials undergoing photoinduced phase transitions (PIPT). Understanding the underlying physical mechanisms driving PIPT is mandatory in order to harvest the peculiar properties of these materials. Various ultrafast studies were performed in cyanidebridged bimetallic assemblies, using time-resolved optical, ${ }^{[7]}$ Raman, ${ }^{[8]} \mathrm{X}$-ray diffraction ${ }^{[9]}$ and X-ray spectroscopy. ${ }^{[10]}$

[a] Giovanni Azzolina, Prof. Eric Collet, Dr Celine Mariette, Dr Marco Cammarata, Dr Elzbieta Trzop, Dr Roman Bertoni, Univ Rennes, CNRS, IPR (Institut de Physique de Rennes) - UMR 6251, F-35000 Rennes, France

E-mail: eric.collet@univ-rennes1.fr, roman.bertoni@univ-rennes1.fr https://ipr.univ-rennes1.fr/interlocuteurs/eric-collet

https://ipr.univ-rennes1.fr/interlocuteurs/roman-berton

[b] Dr Mathias Sander, Dr Matteo Levantino, European Synchrotron Radiation Facility, F-38000 Grenoble, France.

[c] Dr Kosuke Nakagawa, Prof. Shin-ichi Ohkoshi,

Department of Chemistry, School of Science, The University of Tokyo, 7-3-1 Hongo, Bunkyo-ku, Tokyo 113-0033, Japan.

[d] Prof. Hiroko Tokoro

Division of Materials Science, Faculty of Pure and Applied Sciences, Univ Tsukuba, 1-1-1 Tennodai, Tsukuba, Ibaraki 305-8577, Japan.

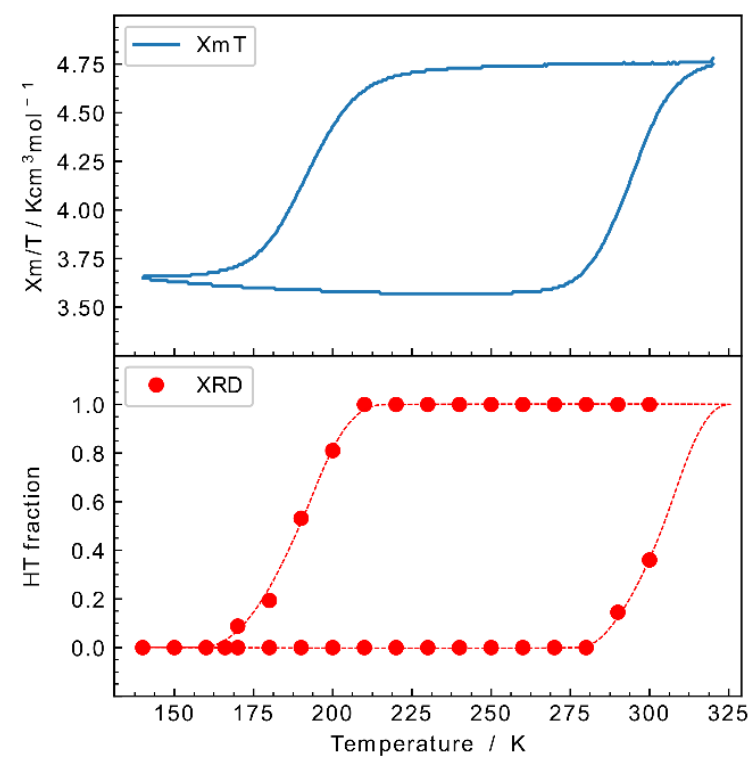

Figure 1. Thermal transition probed through the $\chi_{M} . T$ product $\left(\chi_{M}=\right.$ molar magnetic susceptibility and $T=$ temperature, top) and the HT phase fraction (bottom) obtained by using Rietveld refinement of full X-ray diffraction pattern.

Here we investigate PIPT in rubidium manganese hexacyanoferrate systems ( $\mathrm{RbMnFe}$ ) with general composition $\left.\mathrm{Rb}_{\mathrm{x}} \mathrm{Mn}\left[\mathrm{Fe}(\mathrm{CN})_{6}\right]_{(\mathrm{x}+2) / 3} \cdot \mathrm{ZH}_{2} \mathrm{O}\right)$, by using X-ray diffraction. In these systems, the charge transfer process is accompanied by a structural Jahn-Teller distortion between a high temperature (HT) cubic $\left(F_{\overline{4} 3 m}\right)$ phase $\mathrm{Fe}^{\text {III }}(\mathrm{S}=1 / 2)-\mathrm{CN}-\mathrm{Mn}^{\prime \prime}(\mathrm{S}=5 / 2)$ and a low temperature $(\mathrm{LT})$ tetragonal $\left(I_{\overline{4}} \mathrm{~m} 2\right)$ phase $\mathrm{Fe}$ "I $(\mathrm{S}=0)-\mathrm{CN}-\mathrm{Mn}^{\prime \prime \prime}(\mathrm{S}=2)$. This transition is associated with a wide thermal hysteresis loop that can be tuned by changing slightly the chemical composition. ${ }^{[6 f,}$ 11] Continuous visible light excitation can drive reversible and magnetic PIPT between these phases at low temperature, ${ }^{[12]}$ and a single laser pulse excitation can also be used for controlling the magnetism. ${ }^{[13]}$ Single-shot laser switching was also observed in the hysteresis domain of bistability: a ns laser pulse $(532 \mathrm{~nm})$ can convert the LT phase to the HT phase above a threshold excitation density, and full conversion can be achieved, as observed by infrared spectroscopy. ${ }^{[14]}$ The infrared probe is very sensitive to the electronic and structural reorganizations accompanying the change of electronic state, through the frequency shift and splitting of the $\mathrm{CN}$ stretching mode. However, this local probe cannot discriminate the nature of the macroscopic conversion mechanism being either a homogeneous process or a phase separation process.

Here we present an X-ray diffraction study of the photoinduced phase transition of the $\mathrm{Rb}_{0.94} \mathrm{Mn}\left[\mathrm{Fe}(\mathrm{CN})_{6}\right]_{0.98} \cdot 2.5 \mathrm{H}_{2} \mathrm{O}$ system, induced by a single laser shot inside the thermal hysteresis. 


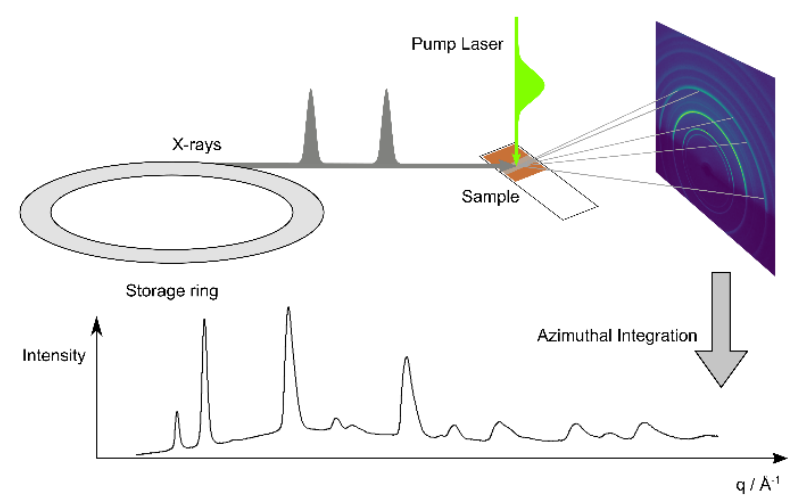

Figure 2. Schematic representation of the setup used for the experiment. The $X$-ray beam from the synchrotron is diffracted by the film of microcrystals deposited on the substrate. A nanosecond pump laser is used for switching the sample inside the thermal hysteresis.

We take advantage of the tight relationship between electronic and structural properties for studying the PIPT process and for showing that a long-range ordered phase forms. Microcrystals of the $\mathrm{Rb}_{0.94} \mathrm{Mn}\left[\mathrm{Fe}(\mathrm{CN})_{6}\right]_{0.98} \cdot 2.5 \mathrm{H}_{2} \mathrm{O}$ system, are particularly interesting for applications, because the bistability region extends above room temperature, as shown by the $\chi_{M}$. T product vs T plot in the upper part of Fig. $1\left(\chi_{M}\right.$ being the molar magnetic susceptibility and $T$ the temperature). ${ }^{[15]}$ The $\chi_{M}$.T value $(\approx 4.75$ $\mathrm{cm}^{3} \cdot \mathrm{K} \cdot \mathrm{mol}^{-1}$ at $\left.300 \mathrm{~K}\right)$ of the HT phase $\mathrm{Fe}^{\mathrm{III}}(\mathrm{S}=1 / 2) \mathrm{Mn}^{\prime \prime}(\mathrm{S}=5 / 2)$ decreases around $T_{1 / 2} \downarrow \approx 185 \mathrm{~K}$ on cooling, as the $\mathrm{LT}$ phase $\mathrm{Fe}^{\prime \prime}(\mathrm{S}=0) \mathrm{Mn}^{\text {III }}(\mathrm{S}=2)$ forms. Conversely, on warming the sample from the LT phase, the $\chi_{\mathrm{M}}$. T value increases around $T_{1 / 2} \uparrow 300 \mathrm{~K}$, and reaches the one of the HT phase. The width of the thermal hysteresis loop is $\approx 115 \mathrm{~K}$.

Fig. 2 shows a schematic of the experimental setup at the ID09 beamline of the ESRF synchrotron (experimental section). X-ray pulses of $14.8 \mathrm{keV} \mathrm{X}$-rays were used to monitor the diffraction signal of a thin film of RbMnFe microcrystals as function of temperature. We also measured the diffracted signal before and after single laser shots ( $560 \mathrm{~nm}$, pulse duration $5 \mathrm{~ns}$ ) at several fluencies. At this given wavelength, photo-excitation of the material induces LT to HT phase switching. In order to maximize the volume of film probed, a grazing incidence geometry is used. The X-ray data are collected on a 2D detector. The diffraction patterns, showing the diffracted $X$-ray intensity as a function of the scattering wave vector $q\left(\AA^{-1}\right)$ are obtained by azimuthal integration of the signal diffracted on the detector. Because of the diffraction geometry, the peaks are relatively broad compared to previous studies, ${ }^{[15]}$ due to the $\approx 30 \mu \mathrm{m}$ height of the $\mathrm{X}$-ray beam.

\section{Results and Discussion}

For checking the quality of the film and the sensitivity of the experimental set-up for tracking PIPT, we studied first the temperature dependence of the X-ray diffraction signal for monitoring the thermal phase transition. The diffraction patterns measured at $300 \mathrm{~K}$ and $140 \mathrm{~K}$ are shown respectively in the top and bottom part of Fig.3. At $300 \mathrm{~K}$ the sample is fully in the HT phase, whereas at $140 \mathrm{~K}$ it is fully in the LT phase.

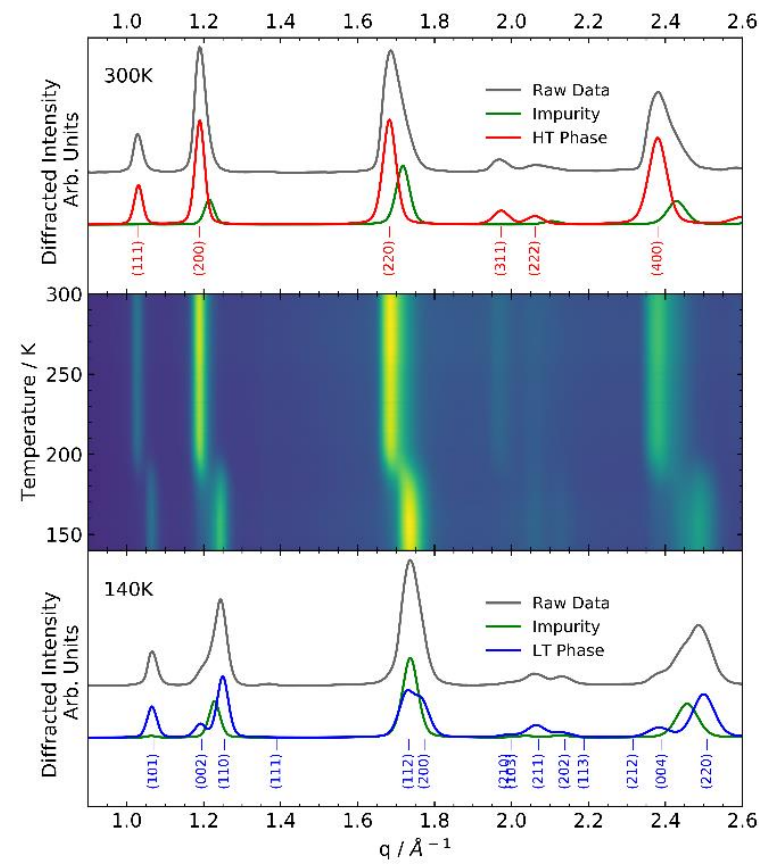

Figure 3. Comparison between the powder diffraction patterns obtained at 300 $\mathrm{K}$ and $140 \mathrm{~K}$. The grey lines represent the raw data, the red line represents the HT phase, the green line represents the impurity and the blue line represents the LT phases patterns, obtained from full pattern Rietveld refinement. The peaks are indexed in the HT and LT cells. The central part shows how the diffracted intensity (colour code) changes with temperature.

The HT and LT diffraction signals obtained by Rietveld refinement are shown in red and blue along with the peak indices. The X-ray diffraction data also reveal a contribution to the signal from a known impurity ${ }^{[15]}$ in the solution used $\left(\mathrm{Rb}_{2} \mathrm{Mn}{ }^{11}\left[\mathrm{Fe}(\mathrm{CN})_{6}\right] \cdot 3.5 \mathrm{H}_{2} \mathrm{O}\right.$, see experimental section), plotted in green. On cooling, during the transition from HT to LT phases, the system undergoes a ferroelastic structural phase transition from a cubic $F_{\overline{4} 3 m}$ to a tetragonal $I_{\overline{4} m 2}$ space group. ${ }^{[15]}$ With this symmetry breaking, the following relationship exists between the lattice parameters of the $\mathrm{HT}$ and LT phases: $\boldsymbol{a}_{\mathrm{HT}}=\boldsymbol{a}_{\mathrm{LT}}-\boldsymbol{b}_{\mathrm{LT}} ; \quad \boldsymbol{b}_{\mathrm{HT}}=\boldsymbol{a}_{\mathrm{LT}}+\boldsymbol{b}_{\mathrm{LT}} ; \quad \boldsymbol{c}_{\mathrm{HT}}=\boldsymbol{c}_{\mathrm{LT}}$. Consequently, the HT Bragg peaks split during the transition towards Bragg peaks of different Miller indices in the LT phase. This can be observed clearly in the middle part of Fig. 3, showing how the diffracted intensity changes as function of temperature. For example, the (200) Bragg peak of the HT phase splits into the (110) and (002) peaks of the LT phase. Around $185 \mathrm{~K}$, one can also observe a coexistence region, where both the Bragg peaks from the HT and LT phases are present. The intensity of the HT peaks decreases as the intensity of the $L T$ ones increases during cooling. This indicates the coexistence of long-range ordered HT and LT domains. The shift of the peaks to higher $q$ at low temperature is associated with the global lattice contraction accompanying the phase transition.

It is also worth noticing that along the full temperature range there is no noticeable shift of the diffracted intensity along $q$ in the LT or in the $\mathrm{HT}$ phases. For the Rietveld refinements we used $a_{H T}=10.5606 \AA$ (at $\left.300 K\right), a_{H T}=10.5592 \AA$ (at $210 K$ ), $a_{\llcorner T}=7.0850 \AA$ and $c_{\mathrm{HT}}=10.5110 \AA$ in agreement with previous results. ${ }^{[15]}$ Indeed the $\mathrm{Rb}_{0.94} \mathrm{Mn}\left[\mathrm{Fe}(\mathrm{CN})_{6}\right]_{0.98} \cdot 2.5 \mathrm{H}_{2} \mathrm{O}$ system is known to show an intrinsic zero thermal expansion of the HT phase and a weak negative thermal expansion of the LT phase ${ }^{[15]}$. We extracted the 
evolution of the HT phase fraction with temperature from the Rietveld refinement, as shown in the bottom part of Fig. 1. On cooling, the diffraction signal of the HT phase decreases around $200 \mathrm{~K}$, where the LT phase appears. This coexistence of HT and LT phases in the hysteresis branch around $185 \mathrm{~K}$ is also observed on warming up from the LT phase: the LT phase signal decreases around $280 \mathrm{~K}$ where the HT phase appears. Our data closely replicate the wide hysteresis loop shown in the magnetic susceptibility measurements (Fig. 1 top) and the values of $T_{1 / 2 \downarrow} \approx 185 \mathrm{~K}$ and $T_{1 / 2 \uparrow} \approx 300 \mathrm{~K}$, which were also observed by previous X-ray diffraction experiments with higher resolution. ${ }^{[15]}$ This confirms that our experiment, despite the unconventional diffraction setup, allows for probing the long-range structural reorganization associated with the change of electronic state from LT to HT phases. Hereafter the similar setup is used for tracking PIPT, which can be permanently induced by a single laser shot inside the thermal hysteresis, as evidenced by infrared spectroscopy. ${ }^{[14]}$

In order to study the effect of a single ns laser pulse on the LT phase inside the hysteresis loop, the sample is cooled down to $120 \mathrm{~K}$ to ensure the full LT conversion and warmed up again to $240 \mathrm{~K}$. The initial state of the sample checked by X-ray diffraction corresponds to the bottom branch of the thermal hysteresis (LT phase). X-ray diffraction signal is then collected before and after exciting the sample with a $560 \mathrm{~nm}$ pulse of light few ns long. This wavelength is used in order to excite both the Mn"II $d-d$ and the intervalence transfer bands of the sample that affect the JahnTeller distortion and the intervalence metal-to-metal charge transfer from $\mathrm{Fe}^{\text {II }}$ to $\mathrm{Mn}^{\text {III }}$ respectively. ${ }^{[16]}$

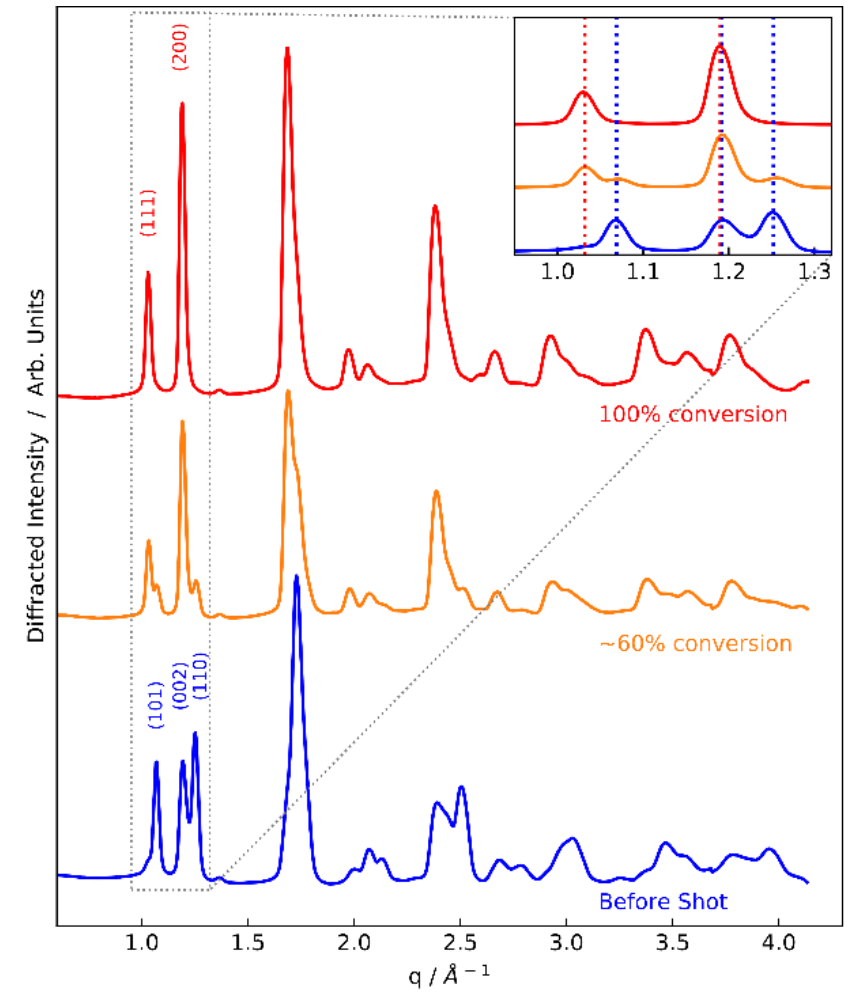

Figure 4. Comparison between diffraction patterns before light irradiation (blue) and after at $\approx 60 \%$ (orange) and $100 \%$ (red) conversion. The inset shows a zoom of the low q region with the indexed peaks of the HT and LT phases. Note that there is no shift in position, only change in relative intensity.
X-ray diffraction data shown in Fig.4 confirm that a nanosecond light pulse transforms the system from the LT to the HT phase. Depending on the energy deposited on the sample, different degrees of LT to HT conversion can be reached. Fig. 4 shows the $X$-ray diffraction patterns in the LT phase before single nanosecond laser shot. After a single laser shot of medium fluence $\left(0.4 \mathrm{~mJ} . \mathrm{mm}^{-2}\right)$, approximately $60 \%$ conversion is reached. With higher fluence of the laser shot $\left(1.02 \mathrm{~mJ} . \mathrm{mm}^{-2}\right)$, full conversion toward the HT phase occurs. The region of the diffraction pattern below $\boldsymbol{q}=1.5 \AA^{-1}$ is particularly sensitive to the change in HT/LT fraction. The inset of Fig. 4 shows how the peaks of the HT phase appear while the ones of the LT disappear after ns laser shot, without noticeable shift in the peak position. This PIPT process corresponds therefore to the development of longrange ordered $\mathrm{HT}$ domains, and this phase nucleation process is very similar to the one observed during the thermal phase transition. The opposite scenario, namely a more homogeneous and local conversion, would result in a gradual shift of the Bragg peaks and/or peaks widening depending on the strain relaxation around the initial photo-induced "trapped" distortions. Such a scenario is ruled-out, as we clearly observe the coexistence of HT and LT phases Bragg peaks when conversion is partial, as shown in Fig. 4 for $\approx 60 \%$ conversion.

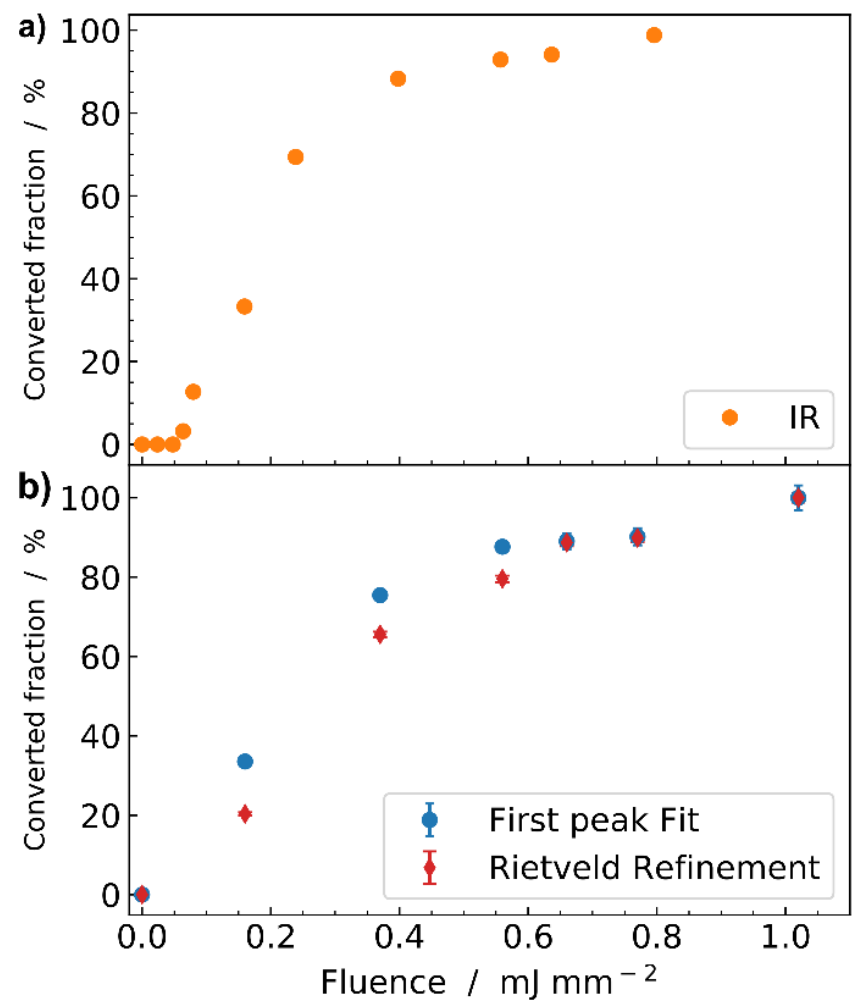

Figure 5. Fraction converted from LT to HT after a single shot as function of the power density. Data in a) are shown in orange and were obtained by IR spectroscopy after ns laser excitation at $295 \mathrm{~K} \cdot{ }^{[14]}$ Data in b) correspond to the present $\mathrm{X}$-ray study performed at $240 \mathrm{~K}$ and the fractions were obtained by using pseudo-Voigt fitting of the intensities of (111) ${ }_{\mathrm{HT}}$ and (101) LT peaks (blue) and by Rietveld refinement of the diffraction pattern (red). 
As a consequence, the relative intensities of the (101) Lт and the $(111)_{\mathrm{HT}}$ Bragg peaks can be trusted to be a good marker of the relative proportion between the HT and LT phases. In Fig. 5, we compare the dependence with the laser pulse fluence of the conversion rate from LT to HT as function of the power of the shot. Fig. 5a shows the data obtained by IR spectroscopy (orange) and reported in a previous work. ${ }^{[14]}$ Fig. $5 b$ shows the present $X$-ray results, obtained by pseudo-Voigt fit of the (101) $)_{\mathrm{LT}}$ and (111) HT $_{\mathrm{HT}}$ peaks (blue) and by Rietveld refinement (red) of the diffraction pattern. The IR data, obtained at $295 \mathrm{~K}$, clearly evidenced a threshold fluence below which no permanent switching is observed in the thermal hysteresis, and a non-linear conversion with the fluence of the ns laser pulse used. The present $X$-ray data obtained at $240 \mathrm{~K}$ reproduce well the trend and a full conversion of the LT phase towards the cubic HT phase is reached with a similar laser fluence $\approx 1.02 \mathrm{~mJ} / \mathrm{mm}^{2}$. The complete macroscopic switching mechanism after a laser pulse excitation is still unknown For spin-crossover materials it was shown that their response to pulsed laser excitation is a multi-step process, ${ }^{[17]}$ which sequentially involves ultrafast trapping of electronic excitation within $100 \mathrm{~s}$ fs, cooperative elastic switching due to volume expansion (ns) and thermal population of high temperature state by laser heating $(\mu \mathrm{s})$. In the present case, the fact that the photoresponses are found to be similar in X-ray and IR experiments performed at two different temperature ( $240 \mathrm{~K}$ and $295 \mathrm{~K}$ ) may indicate that the driving force of the process is not (only) a laser heating process. However, for understanding the relative contribution of electronic and lattice dynamics, and possible elastic and thermal effects, which may be both responsible for the formation of the HT phase, time-resolved studies should be performed to disentangle their respective contributions in the time domain.

\section{Conclusions}

We performed X-ray diffraction experiments on a thin film of the charge-transfer $\mathrm{RbMnFe}$ magnetic material, in order to study the PIPT process induced by a single shot of nanosecond laser. The experimental observations show that the quantity of photoinduced $\mathrm{HT}$ phase varies non-linearly with the laser fluence and that a full conversion from the LT phase to the HT phase is reached at high fluence. The data also show that long-range ordered HT phase domains form after ns laser excitation, giving rise to a phase separation process similar to the one observed at thermal equilibrium. Photo-induced effects and heating process are known to often compete during out-of-equilibrium PIPT induced by a laser flash. However, our experimental data suggest that the process is not only due to laser heating, as the photo-response at $240 \mathrm{~K}$ is similar to the one previously reported at $295 \mathrm{~K}$. The present grazing-incident $X$-ray diffraction technique will be applied for time-resolved studies and combined to other emerging ultrafast techniques, ${ }^{[18]}$ for monitoring in real time the PIPT dynamics.

\section{Experimental Section}

Sample preparation: Plate-shaped microcrystals of $\mathrm{Rb}_{0.94} \mathrm{Mn}\left[\mathrm{Fe}(\mathrm{CN})_{6}\right]_{0.98} \cdot 2.5 \mathrm{H}_{2} \mathrm{O}$ were synthesized by mixing a poyethilene glycol monolaurate (PEGM) matrix containing $\mathrm{MnCl}_{2}$ (aq) and $\mathrm{RbCl}(\mathrm{aq})$ with another PEGM matrix containing $\mathrm{K}_{3}\left[\mathrm{Fe}(\mathrm{CN})_{6}\right](\mathrm{aq})$ and $\mathrm{RbCl}(\mathrm{aq})$. The obtained precipitate was centrifuged, washed in methanol and dried in air as described previously. ${ }^{[15]}$ The formula was confirmed using elemental analysis and infrared spectroscopy. The thin films used for the experiment were obtained by depositing a droplet of a dispersion of microcrystals in ethanol on a thin glass slide $(3 \times 18 \mathrm{~mm})$ and waiting for the solvant to evaporate. An impurity $\mathrm{Rb}_{2} \mathrm{Mn} n^{\prime \prime}\left[\mathrm{Fe}(\mathrm{CN})_{6}\right] \cdot 3.5 \mathrm{H}_{2} \mathrm{O}$ is also present, as observed by X-ray diffraction and chemical analysis (Calculated $\mathrm{Rb}, 21.73$; $\mathrm{Mn}$, 13.92; $\mathrm{Fe}, 13.88 \%$ and found $\mathrm{Rb}, 21.98 ; \mathrm{Mn}, 13.85 ; \mathrm{Fe}, 13.79 \%)$. Even if the synthesis conditions are set up in a similar way, the compositions always slightly differ, ca. \pm 0.06 difference appears in $x\left(\mathrm{Rb}_{x} \mathrm{Mn}\left[\mathrm{Fe}(\mathrm{CN})_{6}\right]_{((\mathrm{x}+2 /) / 3)^{\bullet}} \mathrm{zH}_{2} \mathrm{O}\right)$. It is very likely due to slight differences in temperature, chemical concentration, and stirring speed. Because of such small variations, we perform for each synthesis elemental analysis, magnetic measurement, X-ray structural analysis, etc. to determine the exact composition and properties of the synthesized samples. Above-mentioned situations are common for analog compounds that show similar phase transitions. The direct relationship between composition and phase transition phenomenon is an important topic that was the scope of previous studies. ${ }^{[11]}$

Experimental setup: The experiment was performed at the ID09 beamline of the ESRF synchrotron. The X-ray energy was selected by regulating the gap of the undulator and a Rumultilayer mirror was used to shape the pulse energy spectrum in order to reach a peak energy of $14.8 \mathrm{keV}$. The beam was focused using a toroidal mirror and the beam size at the focal point was $150 \times 150 \mu \mathrm{m}$. The footprint on the sample, due to the grazing angle experimental geometry was $0.150 \times 3 \mathrm{~mm}^{2}$.

For exciting the sample, we used a EKSPLA NT342 laser with a central wavelength of $560 \mathrm{~nm}$ and a pulse duration of $\approx 5 \mathrm{~ns}$. Electronically controlled shutter and waveplate were used to select a single laser pulse and set its energy. Two cylindrical lenses were used to shape the laser pulse profile to a size of $0.3 \times 5.6 \mathrm{~mm}^{2}$, in order to excite a part of the sample larger than the one probed by X-ray diffraction. We performed the measurements by keeping the sample surface at a grazing angle respect to the $\mathrm{X}$-rays incident direction. This was done to match the penetration depth of the X-rays and the laser. The laser direction was perpendicular to the direction of the $\mathrm{X}$-rays as shown in Fig. 2.

The samples were fixed to a goniometer head mounted on a Huber 1-Circle Goniometer (model 410a) with the rotation axis perpendicular both to the $\mathrm{X}$-rays and laser direction. Temperature control during the experiment was achieved using an Oxford Cryosystems Cryostream 800 liquid nitrogen cooler positioned along the rotation axis of the goniometer. The temperature scans were performed using a cooling/heating rate of $6 \mathrm{~K} / \mathrm{min}$.

We collected the diffraction images using a Rayonix MX170-HS CCD plate detector, with an active area of $170 \times 170 \mathrm{~mm}$. The detector was positioned at a distance of around $230 \mathrm{~mm}$ from the sample. Each image was obtained by accumulating the diffracted intensity from several X-ray pulses, 100 for the single shot measurements and 1000 for the temperature scans.

Measurement: The temperature dependent data were collected while continuously changing the temperature of the sample with the cryostream. The single shot data were collected at $240 \mathrm{~K}$. 
However in order to measure inside the hysteresis loop the sample was first cooled down to $120 \mathrm{~K}$ and then warmed up to $240 \mathrm{~K}$. We collected 20 images before the laser shot and 20 images after. Each measurement was performed on a fresh spot of the sample, initially in the full LT state.

Data treatment: The diffraction patterns were obtained by performing an azimuthal integration of the diffraction images using the pyFAl and trx python packages. Before the data treatment the temperature dependent patterns measured within $1 \mathrm{~K}$ were averaged together, also the 20 patterns collected before and after each single shot were averaged as well. The Rietveld refinement was performed using the software TOPAS-Academic version 6 . We refined the peak shapes using a fundamental approach, taking into account the large footprint of the beam on the sample and the effects of preferential orientation on the intensities of the peaks. We also performed a pseudo-Voigt fitting on the intensities of (111) HT $_{\text {T }}$ and (101) LT peaks of the single shot data in order to estimate the converted fraction after each laser shot.

\section{Acknowledgments}

Parts of this research were carried out in the frame of the IM-LED LIA (CNRS) and a JSPS Grant-in-Aid for Specially promoted Research $15 \mathrm{H} 05697$ and JSPS KAKENHI $16 \mathrm{H} 06521$ Coordination Asymmetry. The authors gratefully acknowledge Agence Nationale de la Recherche for financial support under grant ANR-16-CE30-0018 and University Rennes 1 for PhD funding of G.A..

Keywords: Charge transfer - Magnetic properties $\cdot X$-ray diffraction $\bullet$ Photoinduced phase transition

[1] D. N. Basov, R. D. Averitt, D. Hsieh, Nature Materials 2017, 16, 1077.

[2] E. Collet, M. Buron-Le Cointe, H. Cailleau, Journal of the Physical Society of Japan 2006, 75, 011002.

[3] a) M. Gao, C. Lu, H. Jean-Ruel, L. C. Liu, A. Marx, K. Onda, S. Y. Koshihara, Y. Nakano, X. Shao, T. Hiramatsu, G. Saito, H. Yamochi, R. R. Cooney, G. Moriena, G. Sciaini, R. J. Miller, Nature 2013, 496, 343-346; b) S.-y. Koshihara, Y. Takahashi, H. Sakai, Y. Tokura, T. Luty, The Journal of Physical Chemistry $B$ 1999, 103, 2592-2600; c) L. Guerin, J. Hebert, M. B. L. Cointe, S. Adachi, S. Koshihara, H. Cailleau, E. Collet, Physical Review Letters 2010, 105, 246101; d) E. Collet, M. Buron-Le Cointe, M. H. Lemée-Cailleau, H. Cailleau, L. Toupet, M. Meven, S. Mattauch, G. Heger, N. Karl, Physical Review B 2001, 63, 054105; e) E. Collet, M. H. Lemee-Cailleau, M. Buron-Le Cointe, H. Cailleau, M. Wulff, T. Luty, S. Y. Koshihara, M. Meyer, L. Toupet, P. Rabiller, S. Techert, Science 2003, 300, 612-615; f) T. Ishikawa, N. Fukazawa, Y. Matsubara, R. Nakajima, K. Onda, Y. Okimoto, S. Koshihara, M. Lorenc, E. Collet, M. Tamura, R. Kato, Physical Review B 2009, 80.

[4] a) T. Fukaminato, T. Hirose, T. Doi, M. Hazama, K. Matsuda, M. Irie, Journal of the American Chemical Society 2014, 136, 17145-17154; b) M. Irie, T. Fukaminato, K. Matsuda, S. Kobatake, Chemical Reviews 2014, 114, 12174-12277.

[5] a) S. Decurtins, P. Gütlich, C. P. Köhler, H. Spiering, A. Hauser, Chemical Physics Letters 1984, 105, 1-4; b) A. Hauser, Top Curr Chem 2004, 234, 155-198; c) A. Goujon, F. Varret, K.

Boukheddaden, C. Chong, J. Jeftić, Y. Garcia, A. D. Naik, J. C. Ameline, E. Collet, Inorganica Chimica Acta 2008, 361, 40554064; d) K. D. Murnaghan, C. Carbonera, L. Toupet, M. Griffin, M. M. Dirtu, C. Desplanches, Y. Garcia, E. Collet, J. F. Letard,
G. G. Morgan, Chemistry 2014, 20, 5613-5618; e) J.-F. Létard

P. Guionneau, E. Codjovi, O. Lavastre, G. Bravic, D. Chasseau, O. Kahn, Journal of the American Chemical Society 1997, 119, 10861-10862; f) A. Bousseksou, G. Molnar, L. Salmon, W. Nicolazzi, Chemical Society Reviews 2011, 40, 3313-3335; g) E. Trzop, D. Zhang, L. Pineiro-Lopez, F. J. Valverde-Munoz, M. Carmen Munoz, L. Palatinus, L. Guerin, H. Cailleau, J. A. Real, E. Collet, Angew Chem Int Ed Engl 2016, 55, 8675-8679; h) J.

E. Clements, J. R. Price, S. M. Neville, C. J. Kepert, Angew Chem Int Ed Engl 2016, 55, 15105-15109; i) M. A. Halcrow, Spin-crossover materials : properties and applications, Wiley, 2013; j) R. Bertoni, M. Lorenc, A. Tissot, M. L. Boillot, E. Collet, Coordination Chemistry Reviews 2015, 282-283, 66-76; k) E. Collet, H. Watanabe, N. Brefuel, L. Palatinus, L. Roudaut, L. Toupet, K. Tanaka, J. P. Tuchagues, P. Fertey, S. Ravy, B. Toudic, H. Cailleau, Phys Rev Lett 2012, 109, 257206.

[6] a) M. Verdaguer, A. Bleuzen, V. Marvaud, J. Vaissermann, M. Seuleiman, C. Desplanches, A. Scuiller, C. Train, R. Garde, G. Gelly, C. Lomenech, I. Rosenman, P. Veillet, C. Cartier, F. Villain, Coordination Chemistry Reviews 1999, 190-192, 10231047; b) R. Lescouezec, J. Vaissermann, C. Ruiz-Perez, F. Lloret, R. Carrasco, M. Julve, M. Verdaguer, Y. Dromzee, D. Gatteschi, W. Wernsdorfer, Angewandte Chemie-International Edition 2003, 42, 1483-1486; c) A. Dei, Angewandte Chemie International Edition 2005, 44, 1160-1163; d) J. D. Cafun, J. Lejeune, F. Baudelet, P. Dumas, J. P. Itie, A. Bleuzen, Angew Chem Int Ed Engl 2012, 51, 9146-9148; e) H. W. Liu, K. Matsuda, Z. Z. Gu, K. Takahashi, A. L. Cui, R. Nakajima, A. Fujishima, O. Sato, Phys Rev Lett 2003, 90, 167403; f) H. Tokoro, S. Ohkoshi, Bulletin of the Chemical Society of Japan 2015, 88, 227-239; g) K. Komori Orisaku, K. Nakabayashi, S. Ohkoshi, Chem Lett 2011, 40, 586-587; h) K. Zhang, S. Kang, Z S. Yao, K. Nakamura, T. Yamamoto, Y. Einaga, N. Azuma, Y. Miyazaki, M. Nakano, S. Kanegawa, O. Sato, Angew Chem Int Ed Engl 2016, 55, 6047-6050; i) O. Sato, T. lyoda, A. Fujishima, K. Hashimoto, Science 1996, 272, 704-705; j) F. Volatron, D.

Heurtaux, L. Catala, C. Mathoniere, A. Gloter, O. Stephan, D. Repetto, M. Clemente-Leon, E. Coronado, T. Mallah, Chem Commun 2011, 47, 1985-1987; k) M. F. Dumont, E. S. Knowles, A. Guiet, D. M. Pajerowski, A. Gomez, S. W. Kycia, M. W. Meisel, D. R. Talham, Inorganic Chemistry 2011, 50, 4295-4300; I) S. Ohkoshi, S. Takano, K. Imoto, M. Yoshikiyo, A. Namai, H. Tokoro, Nat Photon 2014, 8, 65-71.

[7] D. C. Arnett, P. Voehringer, N. F. Scherer, Journal of the American Chemical Society 1995, 117, 12262-12272.

[8] A. Asahara, M. Nakajima, R. Fukaya, H. Tokoro, S. Ohkoshi, T. Suemoto, Physical Review B 2012, 86.

[9] Y. Moritomo, T. Nakagawa, Y. Fukuyama, N. Yasuda, H. Oosawa, J. E. Kim, H. Kamioka, K. Kato, Y. Tanaka, S. Kimura, F. Nakada, S. Ohkoshi, H. Tanaka, M. Takata, Journal of Physics: Conference Series 2009, 148, 012028.

[10] a) Y. Moritomo, H. Kamioka, T. Shibata, S. Nozawa, T. Sato, S. Adachi, Journal of the Physical Society of Japan 2013, 82, 033601; b) S. Zerdane, M. Cammarata, L. Balducci, R. Bertoni, L. Catala, S. Mazerat, T. Mallah, M. N. Pedersen, M. Wulff, K. Nakagawa, H. Tokoro, S. Ohkoshi, E. Collet, Eur J Inorg Chem 2018, 2018, 272-277.

[11] a) H. Tokoro, S. Ohkoshi, T. Matsuda, K. Hashimoto, Inorganic Chemistry 2004, 43, 5231-5236; b) S. Ohkoshi, T. Matsuda, H. Tokoro, K. Hashimoto, Chem Mater 2005, 17, 81-84; c) H. Tokoro, S. Miyashita, K. Hashimoto, S. Ohkoshi, Physical Review B 2006, 73, 172415.

[12] H. Tokoro, T. Matsuda, T. Nuida, Y. Moritomo, K. Ohoyama, E. D. L. Dangui, K. Boukheddaden, S. Ohkoshi, Chem Mater 2008, 20, 423-428.

[13] H. Tokoro, S. Ohkoshi, K. Hashimoto, Applied Physics Letters 2003, 82, 1245-1247.

[14] H. Tokoro, T. Matsuda, K. Hashimoto, S. Ohkoshi, Journal of Applied Physics 2005, 97, $10 \mathrm{M} 508$.

[15] H. Tokoro, K. Nakagawa, K. Imoto, F. Hakoe, S. Ohkoshi, Chem Mater 2012, 24, 1324-1330.

[16] S. Ohkoshi, T. Nuida, T. Matsuda, H. Tokoro, K. Hashimoto, Journal of Materials Chemistry 2005, 15, 3291. 
[17] a) R. Bertoni, M. Lorenc, H. Cailleau, A. Tissot, J. Laisney, M. L. Boillot, L. Stoleriu, A. Stancu, C. Enachescu, E. Collet, Nat Mater 2016, 15, 606-610; b) R. Bertoni, M. Lorenc, T. Graber, R. Henning, K. Moffat, J. F. Létard, E. Collet, Crystengcomm 2016, 18, 7269-7275.
[18] M. Chergui, E. Collet, Chemical Reviews 2017, 117, 1102511065. 
